\title{
On the issue of automatic form accuracy during processing on $\mathrm{CNC}$ machines
}

\author{
Sobre la precisión automática de la forma durante el procesamiento en máquinas CNC
}

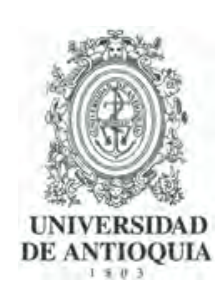

\author{
Victor Ovsyannikov (D)', Roman Nekrasov (D)1, Ulyana Putilova (D) 1, Dmitry Il'yaschenko (D) ${ }^{2 *}$, Elena \\ Verkhoturova (iD ${ }^{3}$ \\ ${ }^{1}$ Department of Technology of Machine Building, Tyumenskiy Industrial'nyy Universitet. Ulitsa Volodarskogo, 38, Tyumen. \\ C. P. 625000. Tyumen, Russian Federation. \\ ${ }^{2}$ Department of Electronic Engineering, National Research Tomsk Polytechnic University. 30 Lenina Avenue, Tomsk. C. P. \\ 634050 Tomsk, Russian Federation. \\ ${ }^{3}$ Research Department, Irkutsk National Reseach Techniical University. Lermontova St, 83, Irkutsk, Irkutsk Oblast. C. P. \\ 664074 Irkutsk, Russian Federation.
}

\section{CITE THIS ARTICLE AS:}

V. Ovsyannikov, R. Yu. Nekrasov, U.S. Putilova, D. P. Il'yaschenko and E. V. Verkhoturova. "On the issue of automatic form accuracy during processing on $\mathrm{CNC}$ machines", Revista Facultad de Ingeniería Universidad de Antioquia, no. 103, pp. 88-95, Apr-Jun 2022. [Online]. Available: https : //www.doi.org/10.17533/ udea.redin. 20201111

\section{ARTICLE INFO:}

Received: June 24, 2020 Accepted: November 17, 2020 Available online: November 17, 2020

\section{KEYWORDS:}

Vibration signal; correlogram analysis; neuro-fuzzy models; correlation entropy; neural network database

Señal de vibración; análisis de correlogramas; modelos neuro-difusos; correlación de entropía; base de datos de redes neuronales

\begin{abstract}
This work aims to develop technical solutions that allow providing the specified parameters of the accuracy of the shape of parts in the cross-section during processing on a CNC machine. Experimental studies were performed on a screw-cutting lathe. An acoustic signal in the range from 6 to $12 \mathrm{kHz}$ was used as a diagnostic sign to assess the wear of the cutting tool, since during preliminary studies, it was found that this range is most sensitive to changes in processing modes. Studies were performed at different values of wear of the cutting tool (estimated by the width of the wear chamfer). For estimating the life of a cutting tool, a neuro-fuzzy model has been developed. Using models of this class allows adjusting to specific conditions (machine, tool), and correctly evaluating the tool life. The model error for the test sample does not exceed $10 \%$. The test results showed that using the proposed solutions makes it possible to increase the accuracy of the manufacturing of shut-off valve parts by $20-30 \%$.
\end{abstract}

RESUMEN: El propósito de este trabajo es desarrollar soluciones técnicas que permitan proporcionar los parámetros especificados de la precisión de la forma de las piezas en la sección transversal durante el procesamiento en una máquina CNC. Se realizaron estudios experimentales en un torno de tornillo. Se usó una señal acústica en el rango de 6 a $12 \mathrm{kHz}$ como señal de diagnóstico para evaluar el desgaste de la herramienta de corte, ya que durante los estudios preliminares se descubrió que este rango es más sensible a los cambios en los modos de procesamiento. Los estudios se realizaron a diferentes valores de desgaste de la herramienta de corte lestimado por el ancho del chaflán de desgaste). Se ha desarrollado un modelo neuro-difuso para estimar la vida de una herramienta de corte. El uso de modelos de esta clase permite ajustarse a condiciones específicas (máquina, herramienta) y evaluar correctamente la vida útil de la herramienta. El error del modelo para la muestra de prueba no supera el 10\%. Los resultados de la prueba mostraron que el uso de las soluciones propuestas permite aumentar la precisión de la fabricación de piezas de la válvula de cierre en un 20-30\%.

\section{Introduction}

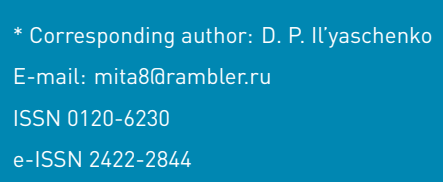

The shape error in the cross-section (ovality, cut) leads to the fact that the contact of the surfaces is developed at separate points, significantly reducing such operational 
Table 1 Influence of shape error on the performance properties of parts and assemblies

\begin{tabular}{lcc}
\hline Operating ability & \multicolumn{3}{c}{ Size and accuracy } \\
\cline { 2 - 3 } & Shape accuracy in the cross-section & Tolerance for size \\
\hline Contact stiffness at the first loading & + & - \\
Contact stiffness at repeated loading & + & - \\
Wear resistance & + & - \\
Connection stightness & + & - \\
Strength of plantings & + & 0 \\
Strength of parts & + & 0 \\
Fatigue strength & 0 & 0 \\
Corrosion resistance & & \\
\hline
\end{tabular}

properties as tightness, durability, and some others. The influence of shape accuracy parameters on performance properties is shown in Table 1.

At the same time, the required parameters of shape accuracy are provided to a greater extent by machining on machines and can be considered as output characteristics of the processing process. A significant factor that affects the provision of the required parameters of shape accuracy is the state of the technological system, primarily the degree of wear of the cutting tool.

Different indicators can be used for evaluation. The most promising is the use of vibroacoustic measurements because, on the one hand, this method has increased sensitivity, which makes it possible to study the processes of finishing. On the other hand, the variety of parameters of vibroacoustic radiation allows the evaluation state of the technological system more correctly.

Some studies were devoted to the use of a vibration signal for evaluating the parameters of mechanical processing. Related works of the scientific school of Bryansk State Technical University (D. N. Petreshin, A. G. Suslovl were committed to the use of an acoustic signal to assess surface roughness. In the works of $V$. L. Zakovorotny, some methods of processing vibration signals were used to assess the wear of cutting tools when processing on multi-purpose machines.

The analysis of the works, as well as some studies [M. Y. Kurilov, A. M. Dalsky, A. K. Ostapchuk, etc.] show that there have been no developments in the field of form accuracy. The work of C.E. Patiño Rodríguez, G.F. Martha de Souza [1] is devoted to the analysis of reliability in hole processing, and the criteria for evaluating reliability are defined. A research [2] is devoted to improving the accuracy of milling operations. At the same time, using fuzzy logic and simulation of the processing process by means of simulation models was performed in the works of José Manuel Arroyo Osorio and co. [3]. Studies by 0. de J. Copete-Murillo and I.D. Arango-López are devoted to improving the efficiency of abrasive processing [4]. Some aspects of ensuring the quality of external cylindrical surfaces are considered in the work of O.J. Zurita-Hurtado and co-authors [5]. The processing of parts with PC bursts was considered by scientists in the article [6]. Moreover, traditional methods of studying vibration signals [7-10], in some cases, give contradictory results. For example, Figure 1 shows the signal spectrum when there are two peaks at multiple frequencies.

This pattern can correspond to two fundamentally different situations: there are two independent rhythms in the structure of the signal studied, or there is a frequency switching effect, and at each moment, we only recorded one rhythm. Thus, we can conclude that the spectrogram does not allow us to fully assess the changes that occur in the technological system when the tool is worn out. In [11-14], intelligent systems are used for recognizing acoustic signal parameters. However, on the one hand, the apparatus of Markov processes and neural networks based on Kohonen maps requires significant and long calculations, which is not applicable in practice to solve the problem of providing output parameters of the processing process. On the other hand, in this case, only the issues of evaluating the wear of the cutting tool are considered.

And here there is a problem with finishing. It consists of the fact that after roughing the surface with a strict tolerance for roundness or alignment, it may be displaced relative to the surfaces used as bases for finishing. Likewise, this displacement may be so large that it is simply impossible to obtain a sufficiently accurate surface when finishing. The result is a defective part. As one way to solve this problem, we propose a method for determining the relative displacement (eccentricity) of the base and processed surfaces directly in the process of 


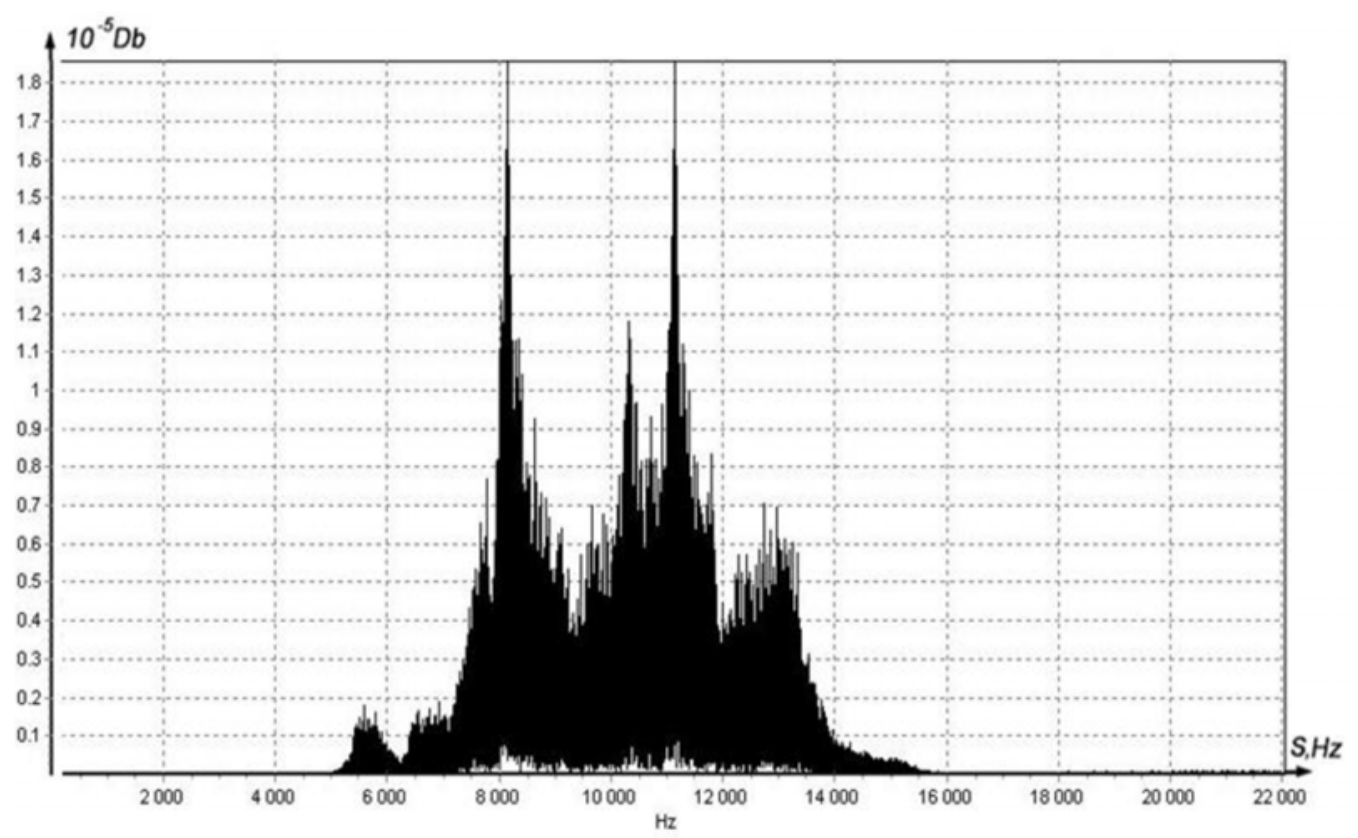

Figure 1 Two-peak signal specter

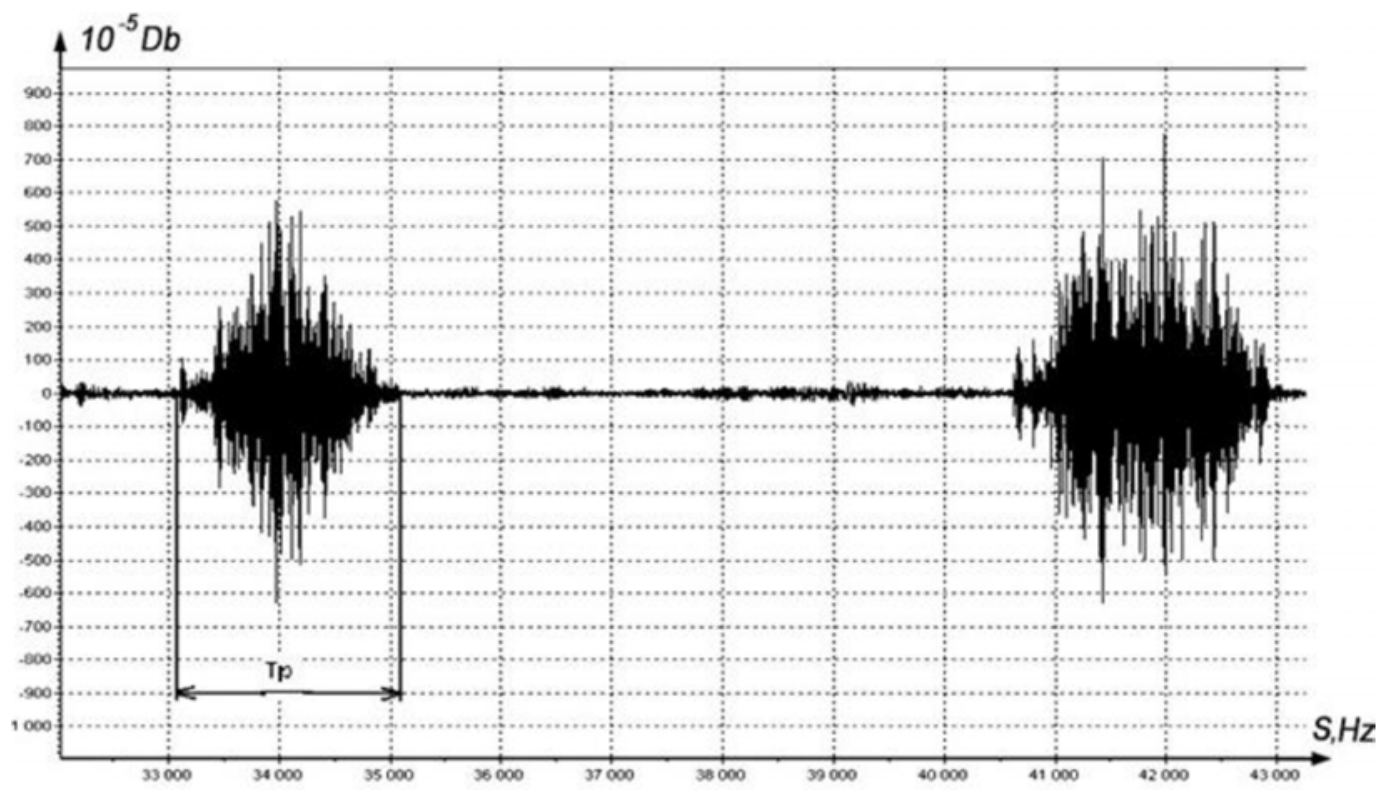

Figure 2 Vibration signal bursts

finishing, or rather at the very beginning, and without any measuring devices. Knowing the value of the eccentricity, we determine whether it is possible to obtain a surface with a given accuracy from the selected bases.

When the tool is slowly brought to the surface of the part (the embedding movement), there is a moment when the tool and the part touch, as shown in Figure 2 with a burst of vibration signal of a certain duration - TP.
Figure 3 shows the dependence of the value of the eccentricity on the value of the angle corresponding to the arc of contact between the tool and the workpiece. Dependencies are presented for five different values of the tuning size.

Thus, it is possible to determine the eccentricity values and make appropriate amendments to the processing operation. It depends on the setting size value, but it is not enough because the parameters of the technological 


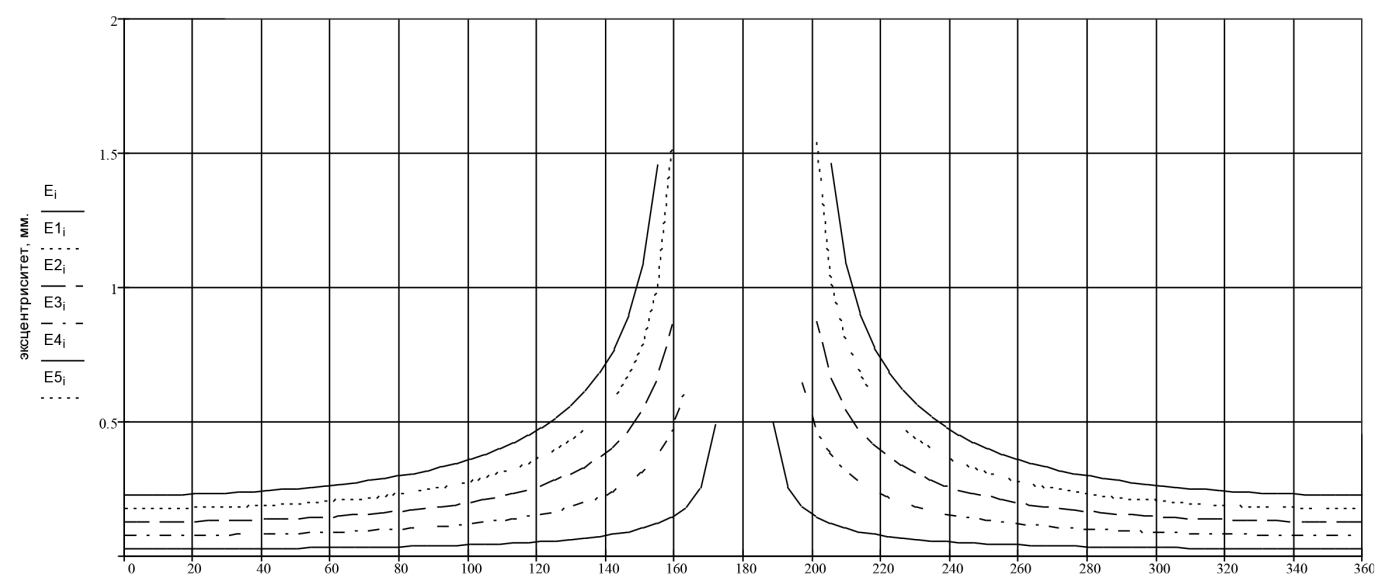

Figure 3 Eccentricity values depending on the contact arc angle

system change during processing. The tool wears out, and this also needs to be taken into account. Moreover, the variety of technological management objects requires the creation of solutions that are capable of self-learning. In this case, a promising direction is the use of artificial intelligence.

This study aims to develop a system for automatically providing non-roundness parameters during the stand processing that includes a lathe with numerical control.

\section{Methods and materials}

The profile that is formed during processing can be represented as the following diagram (Figure 4).

The block diagram of the formation of the profile texture in the cross-section during turning has the form shown in Figure 5.

The task of identifying processing processes can be solved as follows:

- in the process parameters set by the drawing, a model of the surface profile in cross-section is formed, which must be obtained after processing;

- based on the first model, an idea of the input parameter is developed, i.e., the question of choosing a tool and assigning technological modes to ensure a given surface roughness profile is solved;

- based on the analysis of input and output parameter models, the transition function is considered as a model of the processing process.

In other words, the first step is to develop a model describing the output parameters and develop a device for evaluating them during processing. a)

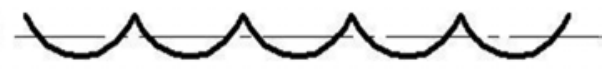

b)

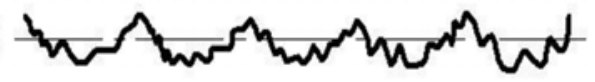

c)

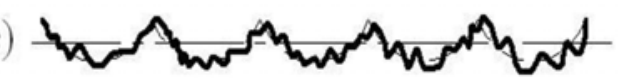

Figure 4 Components of a real profile: (a) systematic component (ideal profile); (b) random component (perturbing effects); (c) real profile

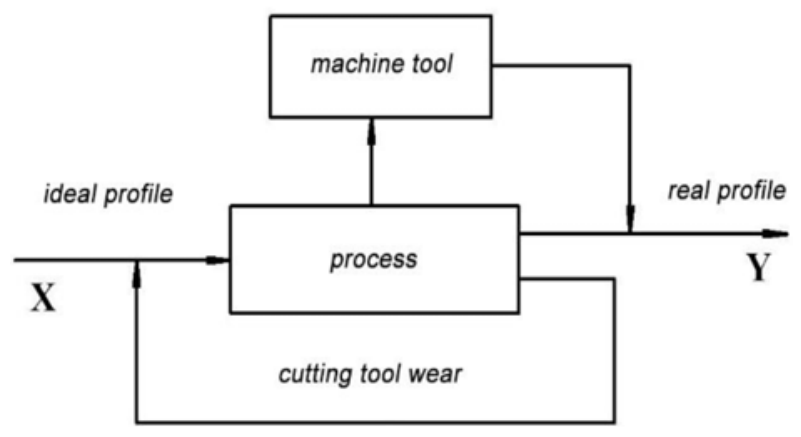

Figure 5 Block diagram of the formation of micro-roughness when turning

During the profile measurements, an array of its coordinates in height $y[i]$ is obtained. A correlation analysis was used to study the cross-section profile $[10,11]$. A normal stationary ergodic process describes the surface profile in the cross-section; then, the main information contains the mathematical expectation and the correlation function $K_{x x}(\tau)$ and, since the centered random process is considered, the problem is reduced to determining the correlation function (1):

$$
K_{x x}(\tau)=\frac{1}{T} \int_{0}^{T} y(t+\tau) y(t)
$$


Replacing the integral by Equation 1 with the sum sign, we get an expression applicable to the profile (2):

$$
K_{x x}(\tau)=\frac{1}{l-\tau} \sum_{i=0}^{i-\tau} y(i) y(i+\tau)
$$

Where $\tau-$ is the variable difference between the abscissas of the profilogram's two sections (correlation step), $\tau$ $=0,1,2, \ldots, \tau_{\text {max }} ; l-$ is the profilograms length; $y(x)$ - are the ordinates of the profile.

The value $K(0)$ was taken into account, i.e., the value $\tau=0$. The calculation process was implemented in the original software (Figure 6).

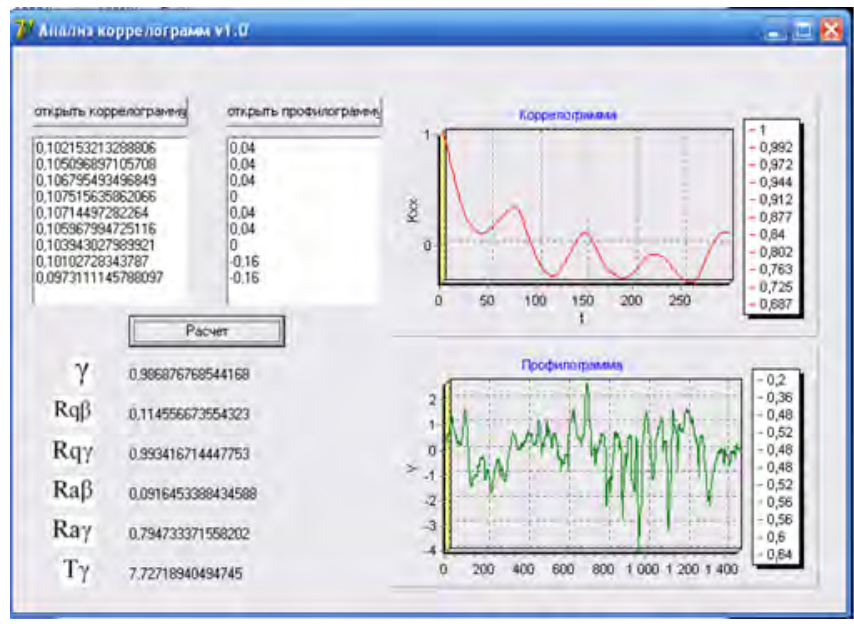

Figure 6 Interface of the program

Standard turning tools made of hard alloys are used as cutting tools. Structural steels are processed. The vibration signal is recorded using an accelerometer sensor installed in the immediate vicinity of the processing area (see Figures 7, 8).

Based on preliminary studies [11], it is found that it is advisable to use a vibroacoustic signal in the frequency range from 6 to $12 \mathrm{kHz}$ to evaluate non-roundness parameters. Processing is performed at different values of cutting speed and feed. It is when the tool wear chamfer on the back surface is from 0 to $2.4 \mathrm{~mm}$. Example of the experiments' series: the material of the parts is 45 , and $40 \mathrm{Cr}$ steel, the material of the cutting tool is VOK 60 . Heat treatment, hardness up to $54 \mathrm{HRC}$. The diameter of the workpieces is $50 \mathrm{~mm}$; the cutting depth is $t=0.2 \mathrm{~mm}$. The number of turns is $630 \mathrm{rpm} . S=20 ; 40 ; 60 ; 80 ; 100 ; 120 \mathrm{~m}$ /min.

The recording is made from a single sensor on the $Y$-axis, on the back of the cutting tool.

The form of the part is measured both on the machine and

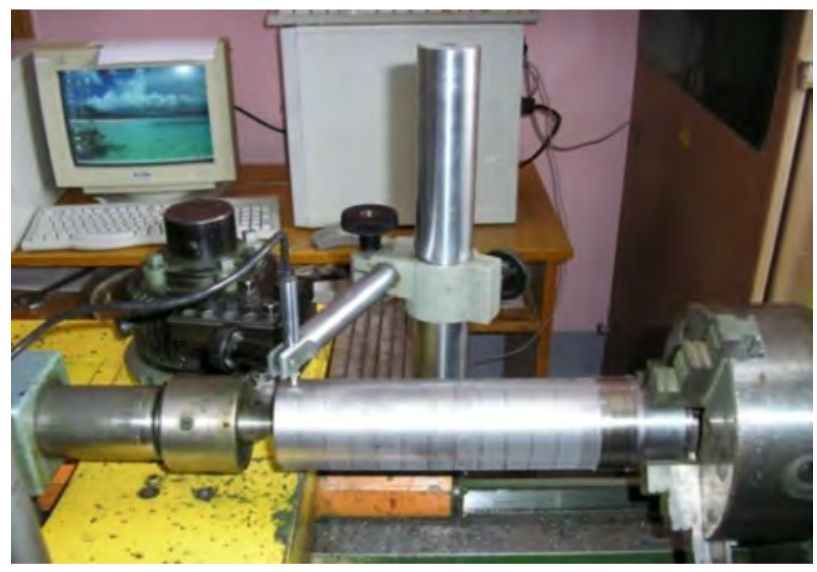

Figure 7 Experimental stand

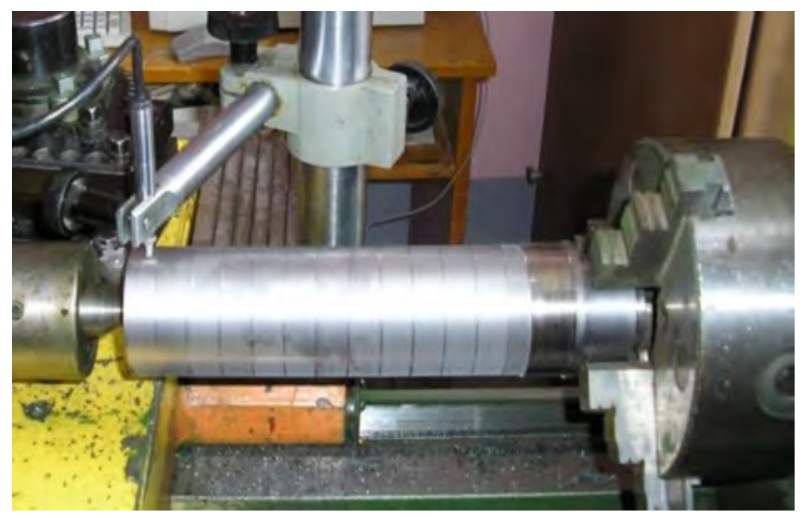

Figure 8 Stand for measuring deviation from roundness

using stands. The price of the inductor dividing is 0.0001 $\mathrm{mm}$ when measuring the deviation from roundness on the machine. The data is recorded in a file; the angle of the part rotation is $3^{\circ}$ (120 measurements on the diameter).

The vibration signal power $S w$ was used as the parameters of the vibration signal (3):

$$
S_{w}=\lim _{T \rightarrow \infty} \frac{\left|F_{t}(w)\right|^{2}}{T}
$$

where $T$ is the signal duration, $F_{t}(w)=$ $\frac{1}{2 \pi} \int_{-0.5 T}^{0.5 T} x(t) e^{-i w t} d t$ fourier transform of the $x(t)$ signal.

The correlation entropy is calculated using the values of the correlation integral using the following formula (4)

$$
K(r, n)=\ln \frac{C(r, n)}{C(r, n+1)}
$$

Where $C(r)=\frac{1}{m(m-1) / 2} \sum_{i=0}^{m-2} \sum_{j=i+1}^{m-1} \theta\left(r-p\left(x_{i}, x_{j}\right)\right)$ - correlation integral.; $\theta(\alpha)=\left\{\begin{array}{c}1, \alpha \geq 0 \\ 0, \alpha<0\end{array}\right\}$ Olivier Heavy side function, $p$ - is the distance in $\mathrm{n}$-dimensional 
phase space, $\mathrm{m}$ is the number of points on $x_{i}$ attractor.

In this case, the recovery of the value attractor is carried out by the Takens theorem (5):

$$
x_{k}=\left(y_{k}, y_{k+\tau}, \ldots, y_{k+(n-1) \tau}\right)
$$

Where $x$-coordinates of the phase trajectory, $y$-values of the time series corresponding to the vibration signal; $\tau$-time delay.

The delay is chosen equal to the time of the first zero intersection of the autocorrelation function according to the Equation 2.

The flow chart of the methodology is shown in Figure 9.

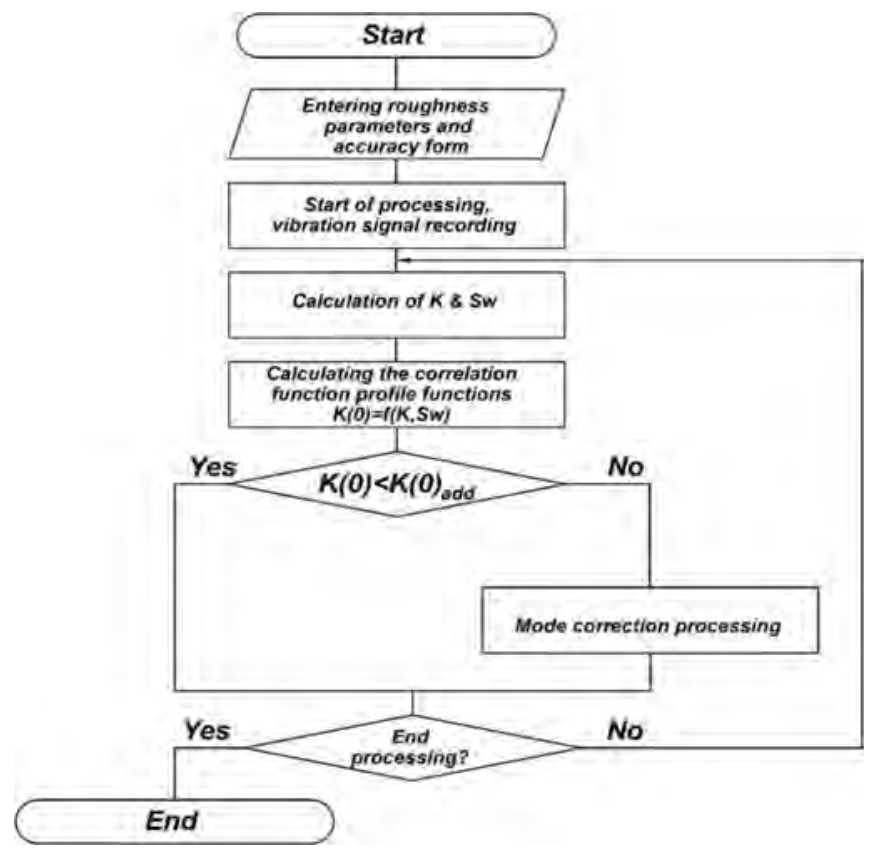

Figure 9 Methodology

\section{Results}

Figures $10-15$ shows the results of experimental studies.

\section{Discussion}

An important feature of the correlation entropy dependence on the wear chamfer width is that it repeats the classical wear curve' character. It can be seen in Figure 16. Three sections can be distinguished: wearing-in, normal, and extremely gross wear. Thus, this parameter can be used to evaluate the tool's performance

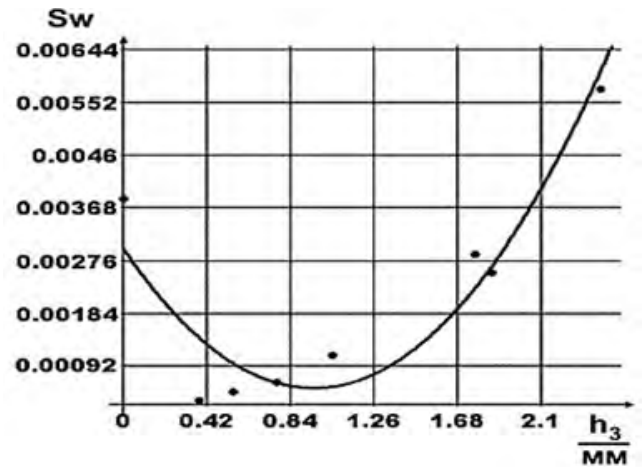

Figure 10 Dependence of the signal power on the wear chamfer width

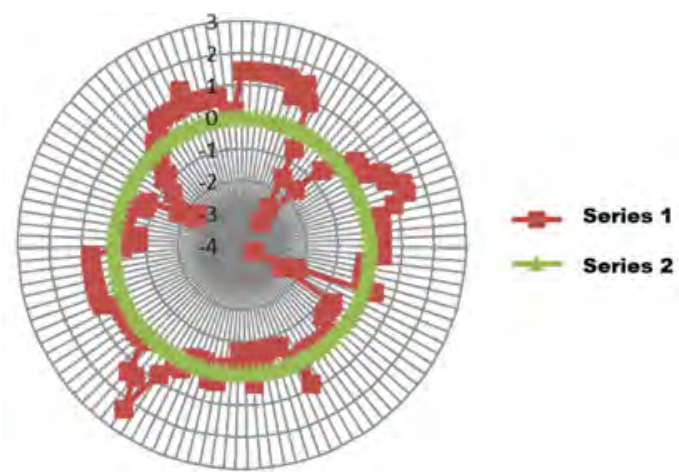

Figure 11 Roundness deviations at feeding $\mathrm{S}=120 \mathrm{~mm} / \mathrm{min}$

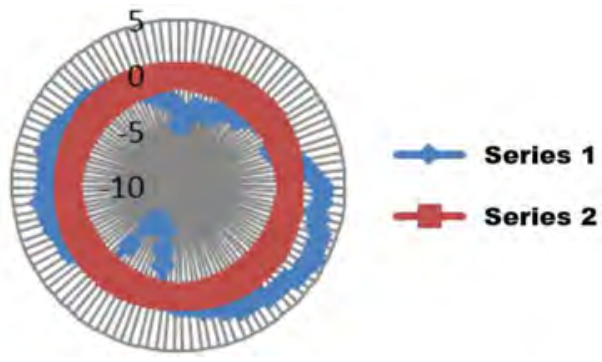

Figure 12 Form error at feeding $\mathrm{S}=0.060 \mathrm{~mm} / \mathrm{rpm}$

The results obtained are used as input data for the model development of the system for automatically ensuring parameters with the form accuracy. The structure is shown in Figure 17.

Training of neural networks of the model is performed on the sample basis. The obtained model accuracy is evaluated by data not included in the training sample. It is found that the average error value is no more than $15 \%$. It should be noted that the use of fuzzy logic in decision-making devices makes it possible to make more effective decisions about the further use of the tool. The test results are shown in Figures 18, 19. 


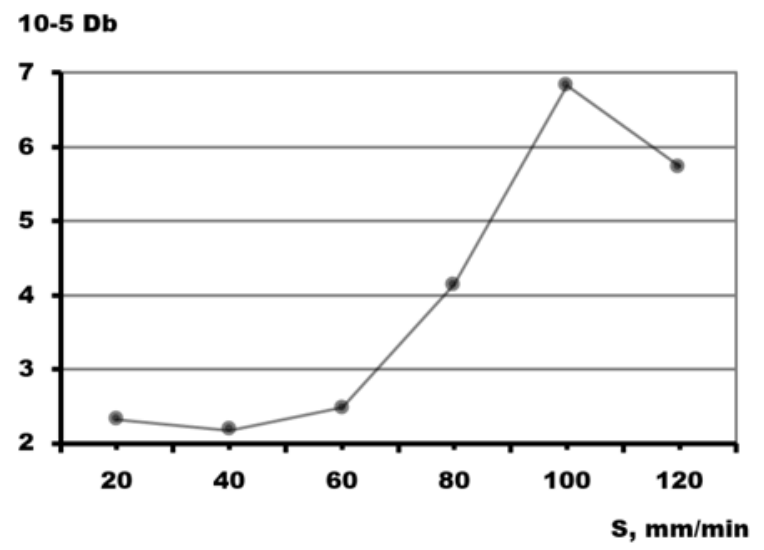

Figure 13 Dispersion of the vibration signal from the feed

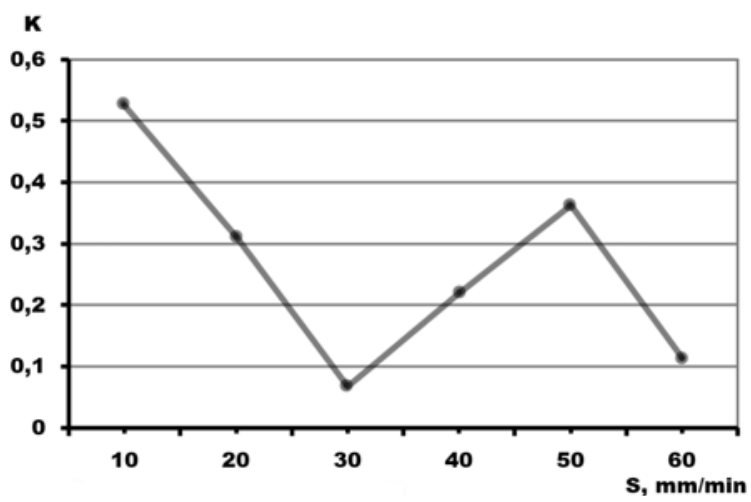

Figure 14 Dependence of the form error on the feed

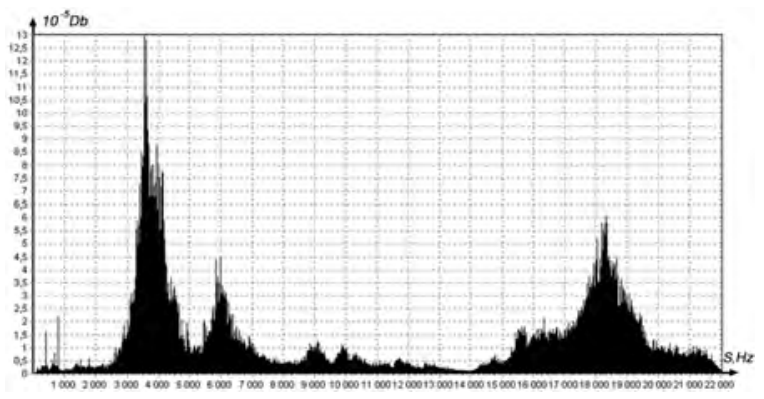

Figure 15 Dependence of the signal power on the wear chamfer width

The advantage of the proposed system is that it can be integrated into the architecture of most CNC machines used in industrial practice without the need to make changes to the machine design.

\section{Conclusions}

The results obtained make it possible to draw some conclusions:

- In the course of the research, it was found that the use

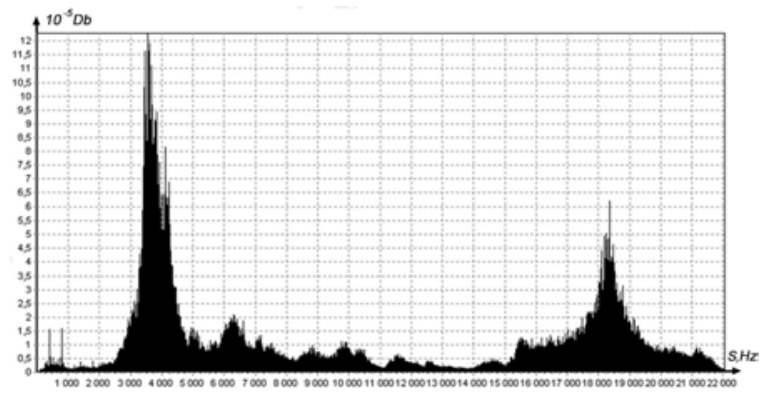

Figure 16 Dependence of the signal power on the wear chamfer width

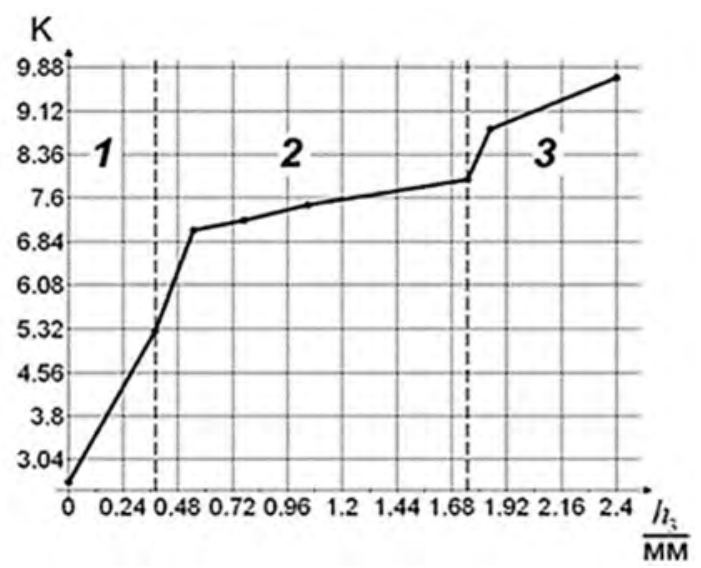

Figure 17 Dependence of correlation entropy on the chamfer wear width

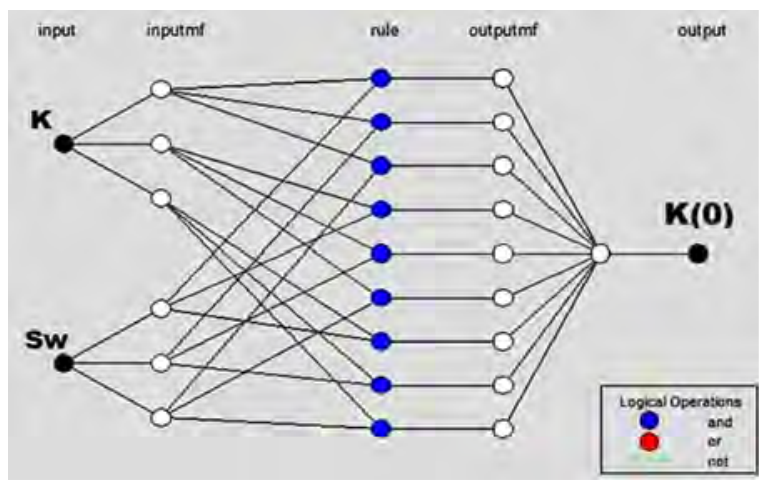

Figure 18 Structure of the system model

of vibration signal parameters (power and correlation entropyl allows not only to evaluate tool wear, as is developed in most similar works, but also to implement active control of the output parameters of the processing process (in this case, the shape error in the cross-section); - the use of neuro-fuzzy models enables building systems for automatically providing parameters of form accuracy with the self-learning possibility;

- The use of neuro-fuzzy models allows us to obtain the 


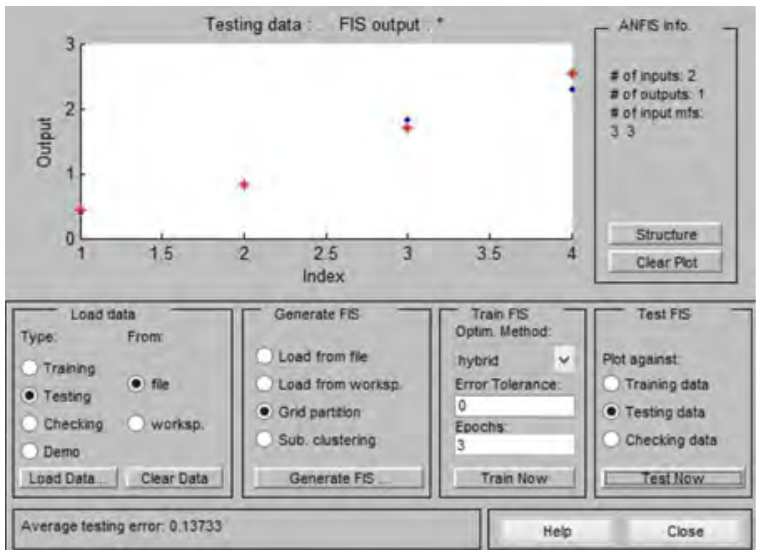

Figure 19 System test results

relationship between the diagnostic feature (vibration signal parameters), and the output parameters of the processing process (shape accuracy in cross-section) with an error of no more than $15 \%$;

- Test results have shown that using the proposed solutions makes it possible to increase the accuracy of the manufacturing of shut-off valve parts by $20-30 \%$.

- Regarding future research, experiments on processing various materials and parts of different stiffness will be considered in order to fill the data Bank. In addition, the resulting model is verified on different types of equipment to identify the influence of machine characteristics on the model parameters.

\section{Declaration of competing interest}

We declare that we have no significant competing interests including financial or non-financial, professional, or personal interests interfering with the full and objective presentation of the work described in this manuscript.

\section{References}

[1] C. E. Patiño and G. F. M. de Souza, "Análisis de confiabilidad para herramientasde corte aplicado al proceso de taladrado," Revista Facultad de Ingeniería, Universidad de Antioquia, no. 36, Mar. 2006. [Online]. Available: t.ly/6a14
[2] F. Beltrán, E. Chávez, A. Favela, and R. F. Vásquez, "Active Perturbation Rejection in Motion Control of Milling Machine Tools," Revista Facultad de Ingeniería, Universidad de Antioquia, no. 69, Oct-Dec. 2013. [Online]. Available: t.ly/LAk8

[3] J. M. Arroyo, E. A. Patiño, D. A. Garzón, and C. J. Cortés, "Modelado del proceso de maquinado mediante el MEF y el uso de metamodelos con lógica difusa y regresión lineal," Revista Facultad de Ingeniería, Universidad de Antioquia, no. 69, Oct-Dec. 2013. [Online]. Available: t.ly/9nsm

[4] 0. D. J. Copete and I. D. Arango, "Selective polishing method to increase precision in large format lightweight machine tools working with petrous material," Revista Facultad de Ingeniería, Universidad de Antioquia, no. 90, Jan-Mar. 2019. [Online]. Available: https://doi.org/10.17533/udea.redin.n90a08

[5] 0. J. Zurita, V. C. D. Graci, and M. C. Capace, "Effect of surface hardness and roughness produced by turning on the torsion mechanical properties of annealed AISI 1020 steel," Revista Facultad de Ingeniería, Universidad de Antioquia, no. 84, Jul-Sep. 2017. [Online]. Available: https://doi.org/10.17533/udea.redin.n984a07

[6] G. Bejarano, J. Caicedo, and J. Muñoz, “Mechanical and tribological properties enhancement of heat treated AISI 4340 steel by using a TiN/TiAlN multilayer coating system," Revista Facultad de Ingeniería, Universidad de Antioquia, no. 44, Apr-Jun. 2008. [Online]. Available: t.ly/WnzT

[7] Z. Hessainia, A. Belbah, M. A. Yallese, T. Mabrouki, and J. F. Rigal, "On the prediction of surface roughness in the hard turning based on cutting parameters and tool vibrations," Measurement, vol. 46, no. 5, Jun. 2013. [Online]. Available: https://doi.org/10.1016/ j.measurement.2012.12.016

[8] M. H. Miguélez, L. Rubio, J. A. Loya, and J. Fernández, "Improvement of chatter stability in boring operations with passive vibration absorbers," International Journal of Mechanical Sciences, vol. 52, no. 10, Oct. 2010. [Online]. Available: https://doi.org/10.1016/j. ijmecsci.2010.07.003

[9] Y. Alammari, M. Sanati, T. Freiheit, and S. S. Park, "Investigation of Boring Bar Dynamics for Chatter Suppression," Procedia Manufacturing, vol. 1, 2015. [Online]. Available: https://doi.org/10.1016/j.promfg.2015.09.059

[10] J. C. Chen and W. L. Chen, "A tool breakage detection system using an accelerometer sensor," Journal of Intelligent Manufacturing, vol. 10, Apr. 1999. [Online]. Available: https://doi.org/10.1023/A: 1008980821787

[11] L. M. D. Owsley, L. Atlas, and G. D. Bernard, "Self-organizing feature maps and hidden Markov models for machine-tool monitoring," IEEE, vol. 45, no. 11, Nov. 1997. [Online]. Available: https: //doi.org/10.1109/78.650105

[12] R. E. Haber and A. Alique, "Intelligent process supervision for predicting tool wear in machining processes," Mechatronics, vol. 13, no. 8-9, Oct. 2003. [Online]. Available: https://doi.org/10.1016/ S0957-4158(03)00005-9

[13] B. Sick, "On-Line and indirect tool wear monitoring in turning with Artificial Neural Networks: A review of more than a decade of research," Mechanical Systems and Signal Processing, vol. 16, no. 4, Jul. 2002. [Online]. Available: https://doi.org/10.1006/mssp.2001. 1460

[14] N. A. Proskuryako, "Fuzzy Controllers in the Adaptive Control System of a CNC Lathe," Russian Engineering Research, vol. 38, Apr. 26 2018. [Online]. Available: https://doi.org/10. 3103/S1068798X18030188 